(i.e., medical technicians, pharmacists and administrators). Reasons of declining influenza vaccination included doubt of the need for the vaccine $(27.8 \%)$, concern of vaccine safety (21.0\%), bad experience following vaccination in the previous year $(41.5 \%)$, insufficient time to attend immunisation clinic $(9.6 \%)$ and fear of the needle $(6.6 \%)$.

Conclusion Number of confirmed influenza cases is mostly under-reported. HCPs are at increased risk for influenza infection and efforts should focus on Infection prevention strategies and increasing immunisation coverage among HCPs and patients.

\section{OCCUPATIONAL HEALTH PRACTICES FOR WASTEWATER TREATMENT WORKERS}

1,2S Porru, ${ }^{2,3} \mathrm{~A}$ Carta, ${ }^{3} \mathrm{~B}$ Bellina, ${ }^{2,3} \mathrm{C}$ Arici*. ${ }^{1}$ Dept. of Diagnostics and Public Health, University of Verona, Verona, Italy; 'University Research Centre 'MISTRAL', University of Brescia, Brescia, Italy; ${ }^{3}$ Dept. of Medical-Surgical Specialties, Radiological Sciences and Public Health, University of Brescia, Brescia, Italy

\subsection{6/oemed-2018-ICOHabstracts.604}

Introduction The increase in the global population entails large production of wastewaters (WW) around the world. WW treatment plants (WWTP) may represent a challenging and hazardous work environment, since various biological agents (viruses, bacteria, fungi, parasites), as well as endotoxins, can be transmitted to the ambient air in WW bioaerosols and cause various disorders. No occupational exposure limit values are currently available. Thus, the potential biohazard $(\mathrm{BH})$ to WWTP workers (WWTPW) has become an increasingly relevant occupational health and safety (OHS) issue. Aims of our contribution are: to provide a state-of-the-art overview on the occupational $\mathrm{BH}$ to WWTPW and to elaborate good OHS practices, based on a field study.

Methods Ten-year (2008-2017) scoping review of articles in the PubMed ${ }^{\circledast}$ database, published in English, French, Italian or Spanish; full text review of the articles. Field study in a sample of 4 WWTP companies managing more than 200 plants overall, with a capacity varying from less than 1000 to more than 870000 population equivalents and employing about 5 to 50 WWTPW. The study entails: collection of OHS documentation on risk assessment and management, health surveillance, education and training; microbiological environmental monitoring (culturable, countable, assayable biological contaminants); investigation on general and specific health data in a sample of WWTPW, by administering a questionnaire regarding socio-demographic aspects, life habits, occupational and clinical history, preventive and protective measures, and by collecting some functional data (e.g. respiratory function); exploring correlations between $\mathrm{BH}$ and $\mathrm{OHS}$ outcomes among WWTPW.

Result Scoping review is ongoing as well as enrolment of WWTP and occupational data collection.

Discussion Main expected results are: assessment of occupational BH in WWTP; development of good OHS practices, particularly on risk assessment, health surveillance, fitness for work, immunisation and preventive practices in WWTP; generation of benchmarks; contribution to the research on occupational limit values for $\mathrm{BH}$.

\section{3 AIRBORNE DISPERSION OF LEPTOSPIROSIS IN A MEAT PROCESSING PLANT}

${ }^{1}$ DJ McLean*, ${ }^{2} \mathrm{M}$ leblanc-Maridor, ${ }^{3} \mathrm{RJ} H a l l,{ }^{3} \mathrm{NE}$ Moore, ${ }^{3} \mathrm{~K}$ Cullen, ${ }^{1} \mathrm{CR}$ Brooks, ${ }^{4} \mathrm{~J}$ Benschop, ${ }^{1} \mathrm{~A}$ 't Mannetje, ${ }^{5} \mathrm{R}$ Weinkove, ${ }^{1} \mathrm{~J}$ Douwes, ${ }^{6}$ NE Pearce. ${ }^{1}$ Centre for Public Health Research, Massey University, Wellington, New Zealand; ${ }^{2}$ Ecole Nationale Veterinaire, Agroalimentation et de I'Alimentation, ONIRIS, Nantes, France; '3nstitute for Environmental Science and Research, Upper Hutt, New Zealand; ${ }^{4}$ Institute of Veterinary, Animal and Biomedical Sciences, Massey University, Palmerston North, New Zealand; ${ }^{5}$ Capital and Coast District Health Board and Malaghan Institute, Wellington, New Zealand; ${ }^{6}$ London School of Hygiene and Tropical Medicine, London, UK

\subsection{6/oemed-2018-ICOHabstracts.605}

Introduction Leptospirosis is the most common occupational zoonosis in New Zealand, with the highest incidence observed in meat processing workers and farm workers. New Zealand has a high incidence of human infection relative to other temperate developed countries, and the organism is widespread in livestock. Serological testing has confirmed infection in livestock presenting to abattoirs and in meat workers. The objective of this study was to determine whether leptospires were present in bioaerosols within the abattoir.

Methods Ambient air samples $(n=18)$ were collected in an abattoir from ovine and bovine processing areas, using a SASS 3100 high volume sampler located adjacent to workers performing exsanguination (halal sticking), pelt removal, evisceration, a splitting saw (bovine only) and boning or meat cutting. Nucleic acid (DNA) in the bioaerosol samples was amplified using multiple displacement amplification (MDA) for metagenomic analysis, but the material was also tested for specific pathogenic species including $L$. interrogans sv Pomona and $L$. borgpetersenii sv Hardjobovis by quantitative PCR. The original (unamplified) DNA samples were also tested.

Result Leptospires were detected in 11 of the (MDA) samples from both ovine and bovine processing areas at the splitting saw, evisceration, exsanguination and pelt removal. There was no evidence of leptospires in samples taken in the boning or meat cutting areas, or in the five blanks taken. Two of the original DNA samples, both from the ovine pelt removal area, also tested positive for leptospires.

Discussion This is the first study to show that leptospires can be detected in a bioaerosol within an abattoir, suggesting a possible route of transmission to meat workers. The organism was detected at locations adjacent to slaughter, pelt removal and evisceration, with the strongest evidence near ovine pelt removal. This distribution directly mirrors the pattern of risk shown in serological testing of meat workers.

\section{Integrated Worker Health and Well Being}

\section{DEVELOPING HEALTHY WORKPLACES IN IRELAND}

Biddy O'Neill*. Health and Wellbeing Programme, Department of Health, Dublin, Ireland

\subsection{6/oemed-2018-ICOHabstracts.606}

Aim of special session To outline key elements in the development of the Healthy Workplace Framework and present Irish worksite case study

Mr. Robert F. Murphy ${ }^{1}$, Dr. Helen $\mathrm{McAvoy}^{2}$, Dr. Margaret Hodgins $^{3}$, Ms. Una Feeney ${ }^{4}$ 